\title{
AGRICULTURA NATURAL: HORTA EM CASA, O CAMINHO PARA MANUTENÇÃO DA SAÚDE E CONSCIENTIZAÇÃO PARA PRESERVAÇÃO DO MEIO AMBIENTE
}

\section{Anderson Murilo de lima ${ }^{1}$}

\author{
Alba Regina Azevedo Arana ${ }^{2}$
}

Resumo: Esta pesquisa visa apresentar a importância para saúde humana de se produzir e disponibilizar no mercado nacional alimentos isentos de agroquímicos advindos da agricultura natural e orgânica e seus impactos positivos para o meio ambiente. Os dados foram obtidos por meio de pesquisas já realizadas confrontadas com informações de pesquisa bibliográfica e práticas de empresas dos segmentos no mercado. Traz a prática da horta em casa como um caminho que pode transformar a cultura individual e familiar no tocante a conscientização da incrementação da saúde e importância da preservação do meio ambiente. Através das informações disponibilizadas na pesquisa, pretende-se levar a população e seus governantes, a importância da agricultura natural, sendo uma das soluções para a qualidade de vida para o mundo moderno. Abordaram-se informações sobre o grau de intoxicação que a população se submete a cada dia advindo da ingestão de produtos alimentícios produzidos convencionalmente, os impactos na saúde e nos ecossistemas, devido a grande quantidade de agrotóxicos utilizados nos modos de produção convencional.

Palavras-chave: Alimento; Saúde; Meio ambiente.

\footnotetext{
1 Especialista em Comércio Exterior e Negócios Internacionais; Mestrado em Meio Ambiente e Desenvolvimento Regional da Unoeste. Bolsista PROSUP/CAPES

${ }^{2}$ Doutora em Geografia; Docente do Mestrado em Meio Ambiente e Desenvolvimento Regional da Unoeste.
} 


\section{INTRODUÇÃO}

A preocupação com a qualidade do alimento consumido pelo homem e os modos de produção agrícola que utiliza produtos externos (adubação, fertilizantes, herbicidas, sementes geneticamente modificadas) as produzidas pela própria terra não é novidade. Uma interessante matéria publicada na revista "Eu Sei Tudo", da segunda década do Século XX, demonstra esta preocupação, onde traz em uma de suas publicações em sua primeira página um artigo intitulado: - "O Perigo da Utilização do Adubo na Produção do Milho".

Segundo Hunt \& Sherman (1972), em seu livro "Economics: An Introduction to Traditional and Radical Views", traduzido por Benchimol, "História do Pensamento Econômico" (1977, p. 25) dizem que a sociedade medieval era essencialmente agrícola. A hierarquia social baseava-se nos vínculos que os indivíduos mantinham coma a terra; as atividades agrícolas sustentavam todo o sistema social. Paradoxalmente, contudo, o crescimento da produtividade agrícola desencadeou uma série de mudanças profundas que se prolongaram por vários séculos, culminando na dissolução do feudalismo medieval e no surgimento do capitalismo.

Principalmente a partir do século $\mathrm{XI}$ a cultura capitalista foi se instalando e o homem foi se tornando cada vez mais ambicioso, levando-o, principalmente no século XXI a se tornar prisioneiro de uma ambição desmedida e que vem, através dela, destruindo o planeta e a si mesmo.

Segundo Santos (apud CAVALCANTI, 2003), o tipo de desenvolvimento que o mundo experimentou nos últimos duzentos anos, especialmente depois da Segunda Guerra Mundial, é insustentável. Assim sendo, são visíveis os impactos resultantes desse modelo, nos quais cerca de metade dos rios estão seriamente contaminados, graves restrições no abastecimento de água, grande proliferação de doenças decorrentes do uso de águas contaminadas. Além disso, as elevadas concentrações de CO2 na atmosfera, efeito estufa, aumento do "buraco" na camada de ozônio, degradação do solo, extinção das espécies devido à degradação do habitat, mudanças no clima, elevação de temperatura dos mares, dentre outros. Esta é uma das fotografias da atualidade. 
Sempre a agricultura e o meio ambiente demonstraram uma relação íntima e inseparável. Diferentemente do que se imaginava, o planeta terra possui recursos esgotáveis e que, se imediatamente do homem não mudar sua postura de egoísta e materialista para uma postura altruísta e espiritualista que o reaproxime das leis da natureza, e, se não forem tomadas ações precisas embasadas nos diversos estudos e pesquisas desenvolvidas que vêm alertando sobre a necessidade de cuidados e preservação do meio ambiente, como disse Okada (1882-1955), filósofo contemporâneo Japonês, o homem irá chegar ao ponto de ter alimentos e não poder se alimentar devido ao alto índice de resquício de agroquímicos nos diversos produtos agrícolas e sofrerá pela falta da naturalidade da natureza.

Este trabalho tem como objetivo principal apresentar a importância da Agricultura Natural como forma ideal para a saúde enfocando a preservação ambiental. Os objetivos específicos são: abordar a agricultura sustentável calcada na não utilização de agroquímicos; apresentar a importância da preservação do meio ambiente e do programa "Horta em Casa e Vida Saudável", não apenas para produzir verduras e legumes em pequenos espaços, mas, como um caminho que leva o indivíduo à aproximação da natureza, ao entendimento de suas leis e seu funcionamento com o ser vivo e biológico.

A metodologia utilizada para catalogação dos dados foi a de realização de oficinas teóricas e práticas pelo "Programa Horta em Casa e Vida Saudável" junto a pessoas convidadas de instituições diversas, como escolas públicas e privadas, ONG`s, simpatizantes da Agricultura Natural e pessoas convidadas pela Fundação Mokiti Okada ${ }^{3}$ em várias regiões do Brasil.

\section{PANORAMA GERAL DA AGRICULTURA E A ALIMENTAÇÃo NA ATUALIDADE}

Na década de 50, nos EUA, foram desenvolvidos, inseticidas, adubos, herbicidas e fungicidas, que conseguiam exterminar fungos, insetos e ervas daninhas, consideradas

\footnotetext{
${ }^{3}$ A Fundação Mokiti Okada (M.O.A), através do Centro de Pesquisa Mokiti Okada - CPMO, vem desenvolvendo há 13 anos pesquisas e tecnologias sustentáveis para as atividades agrícolas e pecuárias, que assegurem a sua viabilidade econômica, respeitando-se o meio ambiente, o bem estar dos agricultores e consumidores, bem como com o desenvolvimento social e econômico da região onde é aplicada, baseadas nos ensinamentos do filósofo Mokiti Okada (Japão, 1882 - 1955).
} 
pragas para os produtores, onde todos passaram a utilizar e com isso iniciando um novo e lucrativo mercado. Nunca a propriedade produziu tanto como depois da aplicação, tornando a produção rentável.

\footnotetext{
1 A Fundação Mokiti Okada (M.O.A), através do Centro de Pesquisa Mokiti Okada - CPMO, vem desenvolvendo há 13 anos pesquisas e tecnologias sustentáveis para as atividades agrícolas e pecuárias, que assegurem a sua viabilidade econômica, respeitando-se o meio ambiente, o bem estar dos agricultores e consumidores, bem como com o desenvolvimento social e econômico da região onde é aplicada, baseadas nos ensinamentos do filósofo Mokiti Okada (Japão, 1882 - 1955).
}

Tudo era muito simples, no aparecimento de insetos: aplicava-se veneno na lavoura, se a terra estava cansada: aplicava-se adubo, se as folhas ficassem doentes: aplicava-se fungicida, passando esses produtos essenciais e utilizados dia a dia na propriedade, tornando com isso os produtores dependentes das indústrias químicas. No Brasil, só iniciou-se na década de 70, impulsionada pelo crédito rural, onde o governo liberava créditos para a utilização dessa nova técnica. (BENEVIDES, 2007).

O crescimento da produção agrícola no Brasil se dava, basicamente, até a década de 50, por conta da expansão da área cultivada. A partir da década de 60, o uso de máquinas, adubos e defensivos químicos, passou a ter, também, importância no aumento da produção agrícola. De acordo com os parâmetros da "Revolução Verde", incorporou-se um pacote tecnológico à agricultura, tendo a mudança da base técnica resultante passado a ser conhecida como modernização da agricultura brasileira (Santos,1986).

SANTOS (apud AGUIAR, 1986) diz que:

Entender, portanto, a modernização da agricultura brasileira como uma simples mudança da base técnica é simplificar, em muito, o seu significado. É importante levar em consideração que a agricultura brasileira sempre se apresentou, ao longo da sua história, subordinada à lógica do capital, sendo um setor de transferência de riquezas. Assim sendo, dentro do seu processo de modernização deve-se dar significado maior à sua transnacionalização e à sua inserção na divisão internacional do trabalho ou, ainda, à penetração do modo de produção capitalista no campo brasileiro (Aguiar, 1986).

Segundo SANTOS \& AGRA (apud CAVALCANTE, 2003), outro impacto negativo da modernização da agricultura é no que diz respeito à produção de alimentos. À medida que o agricultor capitalista toma espaço no campo, incorporando mais e mais terras nas monoculturas de exportação, são reduzidas as áreas ocupadas com o cultivo de alimentos. 
Diante desse contexto, percebe-se a necessidade de um novo direcionamento das diversas atividades econômicas desenvolvidas na sociedade, a exemplo da agricultura, do turismo, dentre outras, para a emergência das questões ambientais, uma vez que essas atividades causam, geralmente, muitos impactos ao meio ambiente, por isso são as que mais sofrem pressões para implantar ações que minimizem os seus impactos relacionados aos aspectos ambientais, sociais e econômicos da atividade. SANTOS \& AGRA (apud CAVALCANTE, 2003).

Embora os agrotóxicos tenham a finalidade de otimizar a produção agrícola, o seu uso indiscriminado representa um risco potencial para a saúde humana e o ambiente. Existem relatos de casos graves de intoxicação por exposição direta ou indireta desses agentes e, portanto, constituem um grave problema de saúde pública.

De acordo ROSSI \& SILVA (apud Moreira et al (2002)), existem três vias principais responsáveis pela contaminação direta em humanos por agrotóxicos: - Via ocupacional intoxicação do grupo de trabalhadores que lidam diretamente com os praguicidas; - Via ambiental distribuição ou dispersão dos agrotóxicos contaminando todos os segmentos ambientais; - Via alimentar contaminação por agrotóxicos devido à ingestão de produtos com resíduos destes compostos químicos atingindo, portanto, uma parcela maior da população, que são os consumidores.

Esta situação ocorre devido aos alimentos (verduras, legumes e frutas) conterem os resquícios de agroquímicos impregnados que trazem incidências cada vez maiores de toxidade aguda, suspeita de toxidade reprodutiva, e, suspeita de desregulação endócrina. Nos animais surgiram a doença da "vaca louca", a gripe aviária, entre outras. Os produtos geneticamente modificados, os chamados transgênicos, também colaboraram para aumentar as dúvidas sobre quais os reais problemas ocasionados pelo seu cultivo e consumo, além de outros que os consumidores sequer têm conhecimento dos seus efeitos, como por exemplo, o uso de vacinas e antibióticos na produção animal.

Assim, temos visto, progressivamente, aumentar a preocupação das pessoas com a qualidade de vida, manifestada, por exemplo, pelas incertezas com relação à qualidade dos alimentos que ingerem diariamente. $O$ que estamos comendo e o que isso pode ocasionar em termos de malefícios ao nosso organismo são algumas das dúvidas que fazem parte, de forma mais frequente, do nosso cotidiano (HESPANHOL \& BARBOSA, 2011). 
Esses fatos revelam a magnitude do problema e as dificuldades derivadas do uso inadequado de agrotóxicos que oferecem riscos à saúde, tanto dos trabalhadores rurais, quanto dos consumidores. Outro aspecto que suscita grandes preocupações é a contaminação do ambiente, ou seja, dos solos, da atmosfera, dos recursos hídricos, dos animais e plantas, HESPANHOL \& BARBOSA (apud BARROS, 2004).

O Artigo 196 da Constituição Federal do Brasil (1988), reza em seu artigo 196 que: "A saúde é direito de todos e dever do Estado, garantido mediante políticas sociais e econômicas que visem à redução do risco de doença e de outros agravos e ao acesso universal e igualitário às ações e serviços para sua promoção, proteção e recuperação".

Neste sentido, vários atores no cenário nacional vêm desenvolvendo trabalhos, estudos e pesquisas sobre os modos de produção, a alimentação moderna e os impactos na saúde humana e no meio ambiente.

Um desses atores é a Agência Nacional de Vigilância Sanitária - ANVISA que entre suas funções tem o papel de trabalhar a regulação dos agrotóxicos:

- Regulamentar, controlar e fiscalizar os produtos e serviços que envolvam riscos à saúde humana, na sua área de competência; e,

- Propor, acompanhar e avaliar as atividades de monitoramento dos resíduos de agrotóxicos, componentes e afins, drogas veterinárias e outras substâncias tóxicas em alimentos. (SILVA, 2012).

A ANVISA implantou o "Programa de Análise de Resíduos de Agrotóxicos em Alimentos - PARA" e emite relatórios anuais de atividades através de sua Gerência Geral de Toxicologia. Em sua metodologia utiliza-se da coleta dos alimentos (amostras) nos estados da federação com o objetivo de verificar se os produtos comercializados possuem a qualidade exigida pela lei que autoriza o uso dos agrotóxicos, e que os limites máximos de resíduos estejam de acordo com o estabelecido pela ANVISA.

A Figura 01 apresenta a distribuição dos resíduos de agrotóxicos nas 2.488 amostras analisadas. Em 37\% delas, não foram detectados resíduos; 35\% apresentaram resíduos abaixo do LMR estabelecido; e 28\% foram consideradas insatisfatórias por apresentarem resíduos de produtos não autorizados ou, autorizados, mas acima do LMR. 


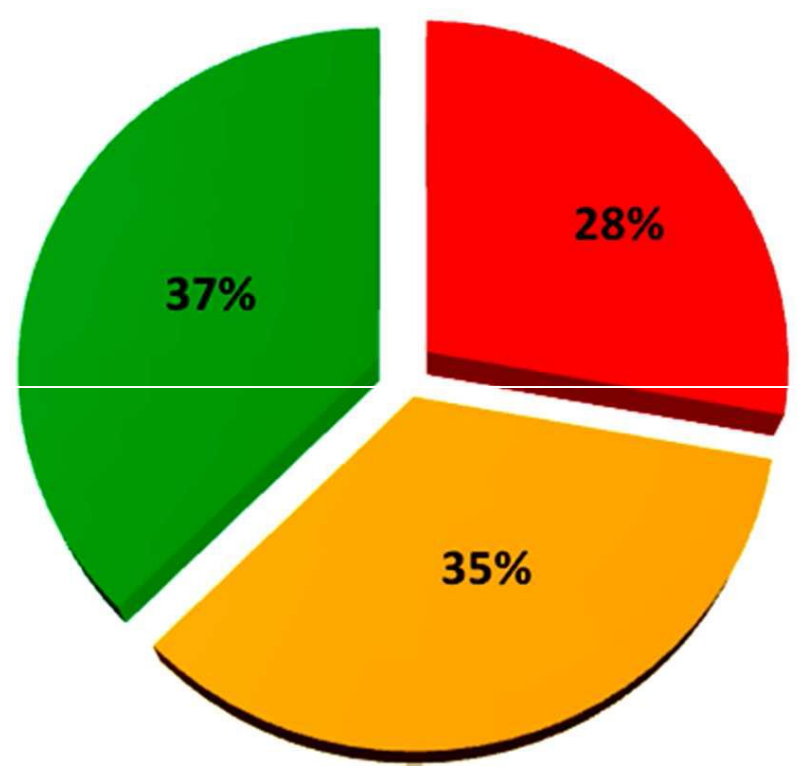

Total de amostras insatisfatórias

Total de amostras satisfatórias com resíduo

- Total de amostras sem residuos

Figura 01: Distribuição das amostras segundo a presença ou a ausência de resíduos de agrotóxicos. PARA, 2010.

Das 2.488 amostras, 694 (28\%) foram consideradas insatisfatórias e as principais irregularidades, considerando os IA pesquisados, foram:

- presença de agrotóxicos em níveis acima do LMR em 42 amostras, correspondendo a $1,7 \%$ do total;

- constatação de agrotóxicos não autorizados (NA) para a cultura em 605 amostras, correspondendo a $24,3 \%$ do total e

- resíduos acima do LMR e NA simultaneamente em 47 amostras, correspondendo a $1,9 \%$ do total.

As amostras insatisfatórias com níveis de agrotóxicos acima do LMR evidenciam sua utilização em desacordo com as determinações presentes nos rótulos e bulas: maior número de aplicações, quantidades excessivas de agrotóxicos aplicados por hectare, por ciclo ou safra da cultura, e não cumprimento do intervalo de segurança ou período de carência 4 .

Por outro lado, os resultados insatisfatórios devido à utilização de agrotóxicos não autorizados resultam de dois tipos de irregularidades:

\footnotetext{
${ }^{4}$ Intervalo de segurança ou período de carência: corresponde ao intervalo de tempo entre a última aplicação de agrotóxicos e a colheita da cultura.
} 
- seja porque foi aplicado um agrotóxico não autorizado para aquela cultura, mas cujo IA está registrado no Brasil e com uso permitido para outras culturas;

- seja porque foi aplicado um agrotóxico banido do Brasil ou que nunca teve registro no país, logo, sem uso permitido em nenhuma cultura.

Dentre as 694 amostras insatisfatórias, 114 apresentaram resíduos em quantidade inferior a $0,010 \mathrm{mg} / \mathrm{kg}$. Tais quantidades podem provir de uma aplicação ou, também, da contaminação por deriva de agrotóxico aplicado em áreas contíguas, por plantio em solo contendo resíduos remanescentes de cultivo anterior, ou por uso de água contaminada. No entanto, mesmo que em pequenas quantidades, estes resíduos podem representar fatores de risco à saúde.

Observa-se, portanto, que os impactos na saúde humana advindos da utilização de agrotóxicos na produção de diversos produtos, vêm sendo alertadas pelas autoridades governamentais como demonstrado no resultado da pesquisa da ANVISA. Concomitantemente, outras instituições governamentais e privadas vêm se esforçando na tentativa de contribuir para modificação positiva desta fotografia de impactos advindo da postura materialista ambiciosa.

Algumas organizações vêm procurando através de linhas alternativas colaborar para os modos de produção agrícola que respeita as leis da natureza contatenando para resultados na incrementação da saúde humana e preservação do meio ambiente.

\section{HORTA EM CASA: MANUTENÇÃO DA SAÚDE E CONSCIENTIZAÇÃO DA IMPORTÂNCIA DA PRESERVAÇÃO DO MEIO AMBIENTE}

No contexto atual da agricultura, da alimentação, do meio ambiente e da saúde é preciso tecer ações e atividades que promovam novos estilos de desenvolvimento que respeitem as condições específicas de cada agroecossistema, assim como a preservação da biodiversidade e a diversidade cultural, de forma a assegurar que gerações futuras possam usufruir dos "mesmos" recursos existentes hoje no planeta. Deste modo, diferentes princípios agronômicos, ecológicos e socioeconômicos foram fundamentais para nortear uma concepção multidisciplinar, assim como um novo modelo de desenvolvimento e, por conseguinte, a construção da sustentabilidade na agricultura. 
Vários precursores das mais variadas correntes literárias, econômicas, científicas, sociais e da saúde se apresentaram a sociedade nos últimos 100 anos, sendo que no tocante a agricultura e alimentação no século XX surgiram algumas correntes filosóficas abordando novos conceitos e teorias a respeito da produção limpa, verde, ecológica e natural que respeita a grande natureza.

Khatounian (2001, p. 25) sobre o desenvolvimento dos modos de produção teceu:

\begin{abstract}
Assim, o modo de produção baseado em insumos químicos, primeiro fertilizantes, depois biocidas, alcançou todos os quadrantes geográficos do planeta, em maior ou menor intensidade, o mesmo ocorrendo com a poluição industrial. Disso resultou que os problemas trazidos pela poluição industrial e pela agricultura mumificada igualmente se generalizaram pelo mundo. Resultou também num grande número de reações, buscando o desenvolvimento de modos de produção mais naturais ou ao menos de menor impacto no ambiente.
\end{abstract}

Sobre as linhas alternativas de produção alimentar que respeita as leis da natureza, Khatounian (2001, p. 26), sobre a Agricultura Natural descreve:

No Japão, nas décadas de 1930 e 1940, desenvolveu-se um movimento de caráter filosófico-religioso, cuja figura central foi Mokiti Okada [...]. Um dos pilares desse movimento foi o método agrícola denominado Shizen No Hou, traduzido como o "método natural" ou agricultura natural [...].

Segundo Okada (1953, p. 169), o princípio básico da Agricultura Natural consiste em fazer manifestar a força do solo. Até agora o homem desconhecia a verdadeira natureza do solo [...]. Tal desconhecimento levou-o a adotar o uso de adubos e acabou por colocá-lo em estado de dependência em relação a eles [...].

Higa (1991), sobre a agricultura natural diz:

Não é nada fácil reconsiderar a Agricultura sob o seu aspecto original da criação. Mas acredito que, se analisarmos os vários problemas que a envolvem a partir de uma posição diferente do sistema técnico atualmente predominante, isto é, se formos ver por uma ótica totalmente nova, poderá ser aberto o caminho para solucionar a situação atual. Está se formando uma consciência comunitária de que será difícil solucionar os problemas fundamentais da Agricultura através da continuidade dos atuais métodos que usam abusivamente fertilizantes e defensivos químicos [...].

O estado normal da Natureza é realizar a manutenção da vida através da alimentação, então o que o homem está fazendo com ela? Porque a sociedade não acorda para sua situação de droga dependência? Seja na agricultura ou nas criações de animais, apresentam-se forte utilização de agroquímicos e antibióticos, produzem-se alimentos sintéticos sem energia vital, vitaminas tecnicamente processadas, promotores 
de crescimento, e etc. O ser humano entrou num círculo vicioso errado na manutenção de sua saúde, tornando-se escravo de uma alimentação vistosa, mas, intoxicada, de má qualidade e sem sabor.

Neste sentido, Okada (1950, p. 41), ao tratar sobre a verdadeira saúde do homem diz: "Para explanar sobre o assunto, devo dizer inicialmente que a verdade, em matéria de saúde, está na adaptação e no respeito à natureza. Essa é a condição fundamental [...]. Mas o que descobrimos ao examinar o corpo humano em estado anormal? Em primeiro lugar ressalta que ele está em desacordo com a Natureza”.

Okada (1950, p. 155), em seu artigo intitulado “A Comédia da Nutrição”, diz:

Não seria preciso explicar, a essas alturas, que o alimento serve para manter a vida; na interpretação deste aspecto, porém, há uma grande diferença entre a teoria atual e a realidade. Quando o homem ingere um alimento [...]. As partes necessárias são absorvidas, enquanto o resto é eliminado. Até chegar a esse processo, entram em ação diversos órgãos, como o fígado, a vesícula biliar, os rins, o pâncreas e outros, que extraem, produzem e distribuem os nutrientes necessários ao sangue, músculos, ossos, pele, cabelos, dentes, unhas, etc. Assim, é realizada incessantemente a atividade de manutenção da vida. Trata-se de uma misteriosa obra da criação, impossível de ser expressa por meio de palavras. É esse o estado normal da Natureza.

Questões ambientais e movimentos filosóficos são importantes para alertar a população e autoridades sobre a quantidade de produtos prejudiciais a saúde que estão sendo disponibilizados na sociedade de modo intenso e sem respeito as leis naturais..

A FUNDAÇÃO MOKITI OKADA (2004, p. 11), sobre a alimentação descreve:

Comparadas com 0 passado, as condições alimentares melhoraram significativamente. Contudo, a cada ano, apesar do grande progresso da Medicina e da Nutrição, o número de pessoas que contraem câncer, doenças degenerativas, neuroses, etc., têm aumentado. Uma das causas tem sido aos aditivos alimentares, de efeito pernicioso. Mas não só eles: podemos dizer que, fundamentalmente, o vilão é o hábito alimentar antinatural, criado pela civilização científica e tecnológica moderna da supremacia materialista.

Para melhor conduzir as atividades da Agricultura Natural junto à população Brasileira, em outubro de 2010 a M.O.A. instituiu a Secretaria da Agricultura Natural SAN sediada na cidade de São Paulo.

Com o objetivo de expandir o conceito e prática da Agricultura Natural preconizado por Mokiti Okada e colaborar para a mudança do estilo de vida alimentar para promoção da verdadeira saúde humana, A M.O.A., desenvolveu e vem implantando nos estados do Brasil, o programa "Horta em casa e Vida Saudável" desde o ano de 2010, com objetivo de conduzir os participantes ao encontro do espírito da Natureza, desenvolvendo o amor 
altruísta e a sensibilidade individual que promove o entendimento da importância da preservação do meio ambiente.

O Programa Horta em Casa \& Vida Saudável busca de forma sistêmica o fortalecimento dos laços familiares e o desenvolvimento das relações sociais, promovendo conceitos de sustentabilidade.

Segundo a Secretaria da Agricultura Natural (2012), o cultivo de plantas é a forma mais prática de estar em contato com a Natureza, aprendendo a respeitar o tempo certo em nossas vidas, não se deixando levar pelo imediatismo do dia-a-dia. A Agricultura Natural visa à obtenção de produtos saudáveis, que incrementem a saúde do homem sem prejudicar o meio ambiente. Aprender com a Agricultura Natural é respeitar a Natureza, adotar a sua lei e praticá-la.

A Metodologia desenvolvida para o Programa Horta em Casa \& Vida Saudável traz em sua aplicabilidade quatro pontos:

- É uma atividade familiar;

- Resgata a gratidão a alimentação ao produtor e a nossos ancestrais;

- Pratica que nos faz compreender atividades de sustentabilidade social e ecológica;

- Meio de Adquirir a Saúde verdadeira.

Segundo a Secretaria da Agricultura Natural (2013), alcançaram-se resultados expressivos no período de julho/2012 a Junho/2103, onde foram realizadas 528 oficinas teóricas e práticas em várias localidades inclusive escolas estaduais e particulares. No total participaram 14.579 pessoas, nas regiões de todo o Brasil. Para o desenvolvimento do programa foram formados cerca de 3.223 multiplicadores voluntários que vem atuando em todo o território nacional.

A tabela 01 apresenta por região, os resultados numéricos de multiplicadores e participantes.

Tabela 01: Resultados numéricos de multiplicadores e participantes do Programa Horta em Casa \& Vida Saudável - julho/2012 a Junho/2013. 


\begin{tabular}{|c|c|c|}
\hline & $\begin{array}{c}\text { Números de } \\
\text { Multiplicadores }\end{array}$ & $\begin{array}{c}\text { Número de } \\
\text { Participantes } \\
\text { nas Oficinas }\end{array}$ \\
\hline Região São Paulo Capital & 306 & 1.254 \\
\hline Região Grande São Paulo & 224 & 990 \\
\hline Região São Paulo Litoral & 335 & 944 \\
\hline Região São Paulo Interior & 574 & 1.804 \\
\hline Região Rio capital & 592 & 3.709 \\
\hline Região Grande Rio & 51 & 1.415 \\
\hline Região Centro-Oeste & 876 & 1.837 \\
\hline Região Sul & 26 & 734 \\
\hline Região Nordeste & 209 & 1.462 \\
\hline Região Norte & 30 & 430 \\
\hline Total & $\mathbf{3 . 2 2 3}$ & $\mathbf{1 4 . 5 7 9}$ \\
\hline \multicolumn{2}{|c|}{}
\end{tabular}

Fonte: Relatório anual da Secretaria de Agricultura Natural - M.O.A., 2013.

As oficinas do programa são realizadas para que através do contato com o solo, à percepção de que pertencemos a natureza, descobrindo a existência de uma natureza ao nosso redor, no alimento, na água do banho, no jardim e no ar que respiramos e para nos lembrar de que nossas famílias, nossos ancestrais em algum tempo já foram agricultores.

Com as oficinas aprende-se como preparar o solo para canteiros e vasos, respeitando a natureza, usando apenas material orgânico, e que através da pratica no dia a dia estaremos construindo um mundo melhor e elevando nossa consciência para a importância da preservação do meio ambiente e seu impacto positivo para os seres humanos, animais, vegetais e demais seres, SAN - M.O.A. (2013).

Essas atividades desenvolveram uma grande expansão da Agricultura Natural, permitindo que os multiplicadores e praticantes resgatassem sua essência, purificando seus pensamentos e sentimentos e, encontrassem, assim, o profundo significado da lei da Natureza, SAN - M.O.A. (2013).

Percebeu-se ainda que a prática contínua da horta caseira contribui para o consumo de produtos com elevada energia vital, fundamental para preservar e melhorar a saúde do ser humano, e permite que muitas pessoas se reconectem à Verdade da Lei da 
Grande Natureza, que é o caminho para a salvação da humanidade, SAN - M.O.A. (2013).

Vários relatos de experiências dos praticantes da Horta em Casa estão sendo catalogadas pela SAN - M.O.A, como exemplo breve relato do casal Michelle e Herber, da Região de São Paulo Interior: "Com o envolvimento das filhas molhando as verduras diariamente, passaram a pedir saladas nas refeições, o que antes não acontecia, pois, não comiam. Desta forma, mudaram o comportamento e passaram a fazer as refeições na mesa todos junto a nós.

Estes resultados levaram o Programa Horta em Casa \& Vida Saudável a ser premiada na categoria "Sustentabilidade" na sexta edição do Prêmio Empreendedor Brasil, organizado pela Brasil Notícias Editora e Comunicação Empresarial no mês de Julho de 2013, em São Paulo, REVISTA IZUNOMÊ (Agosto/2013).

Segundo a Secretaria da Agricultura Natural (2011), O prazer de saborear alimentos verdadeiramente saudáveis e com alto valor biológico é algo indescritível aliando ao fato de se produzir estes alimentos pelas próprias mãos então, o sabor se torna duplamente irresistível. O cultivo de plantas é a forma mais prática de estar em contato com a Natureza, aprendendo a respeitar o tempo certo em nossas vidas, não se deixando levar pelo imediatismo do dia-a-dia. A Agricultura Natural visa à obtenção de produtos saudáveis, que incrementem a saúde do homem sem prejudicar o meio ambiente. Aprender com a Agricultura Natural é respeitar a Natureza, adotar a sua lei e praticá-la.

\section{5- CONSIDERAÇÕES FINAIS}

Os modos de produção da agricultura moderna vêm trilhando um caminho calcado no capitalismo e materialismo que não respeita as leis da natureza, a verdade. Apesar de estudos e pesquisas de diversos atores públicos e privados espalhados pelo mundo estarem advertindo sobre os perigos da utilização de agroquímicos na agricultura e seus efeitos negativos na saúde humana e degradação do meio ambiente, a ambição desmedida criada pelo homem esta o levando para destruição bem como a do planeta.

A verdadeira agricultura é aquela que respeita a natureza e a trata com um ser vivo com vontade e sentimento, busca na própria natureza a resposta precisa para uma produção saudável e abundante, promovendo uma sociedade capaz de se desenvolver 
em equilíbrio e ser sustentável. Para se compreender o papel da alimentação na evolução humana, devemos nos lembrar de que a procura pelo alimento, seu consumo e, finalmente, como ele é usado para processos biológicos são, todos, aspectos críticos da ecologia de um organismo M.O.A. (2010).

Apesar do poder de muitas empresas ainda prevalecerem no mercado na disponibilização de alimentos produzidos pelo método convencional, em contrapartida, a consciência alimentar das pessoas vem se modificando paulatinamente, fazendo com que considerável número de indivíduos requeira alimentos livres de agrotóxicos e que em sua produção promova a preservação do meio ambiente.

Como disse Okada (1950), sobre a natureza sem eu poema: "Quando apanho uma folha seca caída no chão, sinto nela a indiscutível Lei do Ciclo da Vida". Neste ciclo o homem se dissociou da natureza criando toda a problemática vivenciada na era contemporânea.

A Horta em Casa é um caminho para que toda a humanidade retorne ao seu equilíbrio original onde há respeito às leis da natureza mantendo o equilíbrio do meio ambiente e a promoção da verdadeira saúde ao homem.

\section{REFERENCIAS}

BENEVIDES, L. “HowStuffWorks - Como funciona a agricultura orgânica” Publicado em 03 de outubro de 2007 (atualizado em 16 de junho de 2008). Disponível em http://planetaorganico.com.br/site/index.php/o-mundo-dos-vinhos-organicos/ Acesso em: 13 set.2013.

BRASIL, Agência Nacional de Vigilância Sanitária - ANVISA. PROGRAMA DE ANÁLISE DE RESÍDUOS DE AGROTÓXICOS EM ALIMENTOS (PARA) - Relatório de Atividades 2010. Brasília, dezembro, 2011. Disponível em: http://portal.anvisa.gov.br/wps/content/Anvisa+Portal/Anvisa/Inicio/Agrotoxicos+e+Toxicol ogia/Assuntos+de+Interesse/Programa+de+Analise+de+Residuos+de+Agrotoxicos+em+A limentos. Acesso em: 04 set.2012.

BRASIL. CONSTITUIÇÃO DA REPÚBLICA FEDERATIVA DO BRASIL DE 1988. 
CORDEIRO, Ângela et al. A insustentabilidade do modelo de desenvolvimento agrícola brasileiro. Brasília: Ministério do Meio Ambiente, 1996, p.1-13 (mimeo).

FUNDAÇÃO MOKITI OKADA - M.O.A.; CENTRO DE PESQUISA MOKITI OKADA. Programa Horta em Casa \& Vida Saudável. Ipeúna - SP, 2010.

HESPANHOL, R. A. M. \& BARBOSA, S. A. FORMAS ALTERNATIVAS DE PRODUÇÃO: a agricultura orgânica no Município de Presidente Prudente - SP. CAMPO TERRITÓRIO: revista de geografia agrária, v. 6, n. 12, p.200-223, ago., 2011.

HIGA, Teruo. Agricultura Natural - A solução do Problema Alimentar. $2^{2}$ ed. São Paulo: Tradução MOA, 1991.

HUNT, E. K. \& SHERMAM, H. J. História do Pensamento Econômico. RJ, 25 ed. Editora Vozes, 2010.

KHATOUNIAN, C. A. A Reconstrução Ecológica da Agricultura. Botucatu: Agroecológica, 2001.

IGREJA MESSIANICA MUNDIAL DO BRASIL. REVISTA IZUNOMÊ: Um novo paradigma para a civilização atual. No. 68, São Paulo: Divisão de Comunicação, 2013.

OKADA, M. A Outra Face da Doença. $2^{a}$ ed. São Paulo: MOA Shoji, 1986.

OKADA, F. M. Alimentação com Energia Vital: Visão de Mokiti Okada. 1ª Ed. São Paulo, Yangrafi, 2004.

SANTOS, Robério Ferreira dos. Análise crítica da interpretação neoclássica do processo de modernização da agricultura brasileira. In: SANTOS, R.F. dos. Presença de viéses de mudança técnica da agricultura brasileira. São Paulo: USP/IPE, p.39-78, 1986.

SANTOS, J.G. Indicadores de Sustentabilidade Para o Turismo: uma proposta de indicadores e critérios de análise para o monitoramento da atividade. SIMPOI, 2012.

SILVA, J. A. A. I SEMANA DE VIGILÂNCIA SANITÁRIA NO CONGRESSO NACIONAL - A ANVISA e o Desenvolvimento Social e Econômico do Brasil. Brasília, maio, 2012. Disponível em: http://www2.camara.leg.br/atividade-legislativa/comissoes/comissoespermanentes/capadr/audiencias-publicas/audiencias-2012/rap-09-de-maio-de-2012anvisa-agenor Acesso em: 13. Set.2013.

SOUZA, M. V. Resíduos de Agrotóxicos Ditiocarbamatos e Organofosforados em Alimentos Consumidos no Restaurante Universitário-UNB: Avaliação da Exposição Humana. 2006. 110 f. Dissertação (Mestrado) - UNB, Brasília, 2006. 